\title{
Arteriovenous Shunting in Quadriplegia
}

F. Van Den Hoogen, L. A. Brawn, S. Sherriff, N. Watson and J. D. Ward Royal Hallamshire Hospital and Lodge Moor Hospital, Sheffield S10 2fF, U.K.

\section{Summary}

Arterio-venous shunting has been demonstrated in the limbs of ten subjects with traumatic quadriplegia, as shown by increased venous oxygen concentration and a Doppler sonogram pattern indicative of continuous forward flow. This phenomenon is similar to that seen in the diabetic neuropathic foot, suggesting that autonomic dysfunction is a major factor in the development of foot ulceration in the quadriplegic and in the diabetic.

Key words: Arteriovenous shunting; Autonomic dysreflexia; Sonogram; Pulsatility index; Pulse wave velocity; Elastic modulus.

\section{Introduction}

Arteriovenous shunting is thought to be a consequence of sympathetic dysfunction although its exact aetiology is unknown. It has been described in the diabetic neuropathic leg (Edmonds, Morrison et al., 1982; Boulton et al., 1982; Scarpello et al., 1978), where its presence is aggravated by rigid calcified vessels, distal small vessel occlusion and metabolic factors (Ward, 1982).

Patients with traumatic quadriplegia are known to have an interruption to the outflow pathways of sympathetic fibres. At four months after injury, they experience episodes of autonomic dysreflexia in response to visceral and cutaneous stimuli (Corbett et al., 1971; Frankel et al., 1979; Tsai et al., 1980). It therefore seemed reasonable to look for evidence of arteriovenous shunting in these patients, and to assess the possible contribution of other factors.

\section{Patients and methods}

Ten quadriplegic patients with cervical cord lesions at C5-C7 were studied $1 \frac{1}{2} 57$ months after their injury. They were all leading active wheelchair lives with no 
evidence of vascular or infective complications. None were taking medication likely to interfere with the central nervous or cardiovascular systems.

All had venous blood samples analysed for haemaglobin, glycosylated haemoglobin, thyroid function tests and oxygen concentration. In addition, they all had doppler blood flow studies performed under controlled conditions, with the patients in the supine position.

A control group of 14 healthy age-matched subjects were also studied: 6 of these had Doppler blood flow studies done under the same conditions as the quadriplegics, and eight of them had venous blood samples taken for oxygen concentration in the rested, supine position but in an uncontrolled environment.

The technique of venous blood sampling was without the use of a tourniquet after 30 minutes rest. It was observed that cannulation and sampling were much easier in the quadriplegics as compared with the controls, although the veins did not appear visibly dilated.

Doppler blood flow studies were carried out using a $5 \mathrm{mHz}$ continuous wave Doppler probe and the pulsatility index (P.I.) was calculated from the sonogram as $\frac{\text { peak to peak height }}{\text { mean area }}$ (Gosling, 1976). The probe was also used to measure the posterior tibial and brachial artery pressure to provide the ankle pressure index (A.P.I.) (Yao et al., 1969).

The pulse wave velocity (P.W.V.) was calculated by comparing signals from the common femoral and posterior tibial arterials with a concurrent E.C.G. monitor and was processed using a Paris 806 Directional Doppler in conjunction with a 2 real time frequency analyser (Smallwood et al., 1977). The P.W.V. was used to calculate the elastic modulus (E.M.), this being a measure of the distensibility of the arterial wall.

Nerve conduction studies were performed in all the quadriplegics on the right peroneal nerve using a Medelec DF06 electrophysiological system and recordings were made over the extensor digitorum brevis (Ward et al., 1971).

Results were analysed using the Mann-Whitney non-parametric test.

\section{Results}

The mean oxygen concentration in the feet of the quadriplegics was significantly higher than in controls $(8.28 \mathrm{kPa}$ vs $5.3 \mathrm{kPa}, \mathrm{p}<0.001)$, and similar results were obtained in the hands of these subjects $(9.78 \mathrm{kPa}$ vs $7.33 \mathrm{kPa}, \mathrm{p}<0.001)$ (Fig. 1).

Calculations from the sonogram (Fig. 2) showed that the pulsatility index was significantly reduced in quadriplegics compared to controls $(2.32$ vs $12 \cdot 1$, $\mathrm{p}<0.001)$. In functional terms this indicates fast forward flow of blood within the vessels of the quadriplegics.

The elastic modulus was also reduced in the quadriplegics as compared with the control group $(0.89$ vs $1.20, \mathrm{p}<0.05)$ indicating more distensible arteries. The ankle index pressure indices were normal in all subjects studied.

Motor nerve conduction studies were normal in all the quadriplegics (mean $47.87 \mathrm{~m} / \mathrm{sec}$, range $44-56 \mathrm{~m} / \mathrm{sec}$ ), demonstrating no peripheral nerve damage. The haemaglobin, glycosylated haemoglobin and thyroid function tests were normal in all patients. 
HANDS

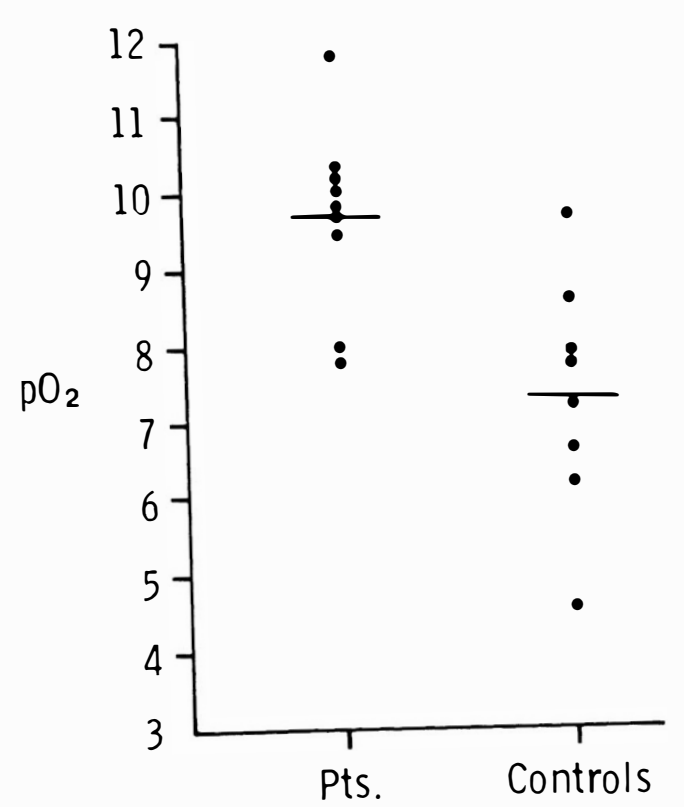

FEET

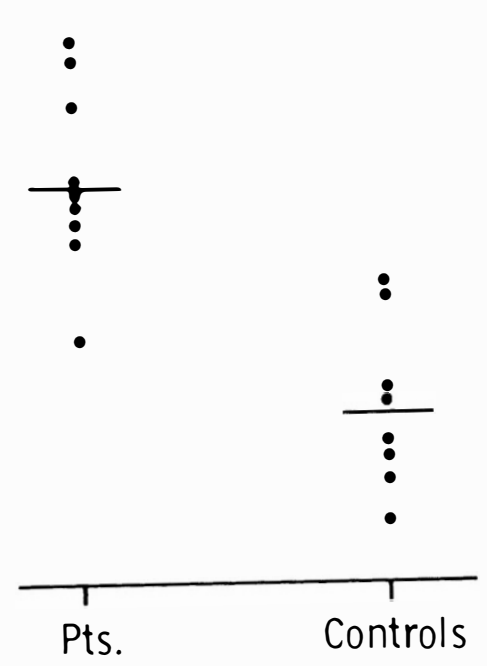

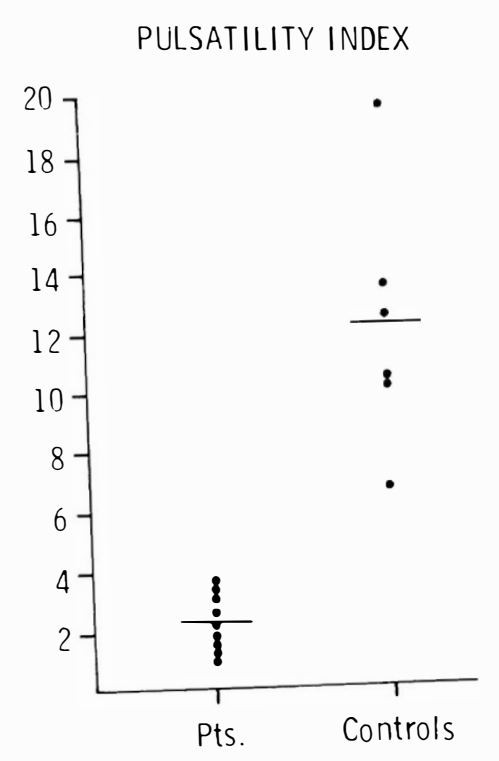

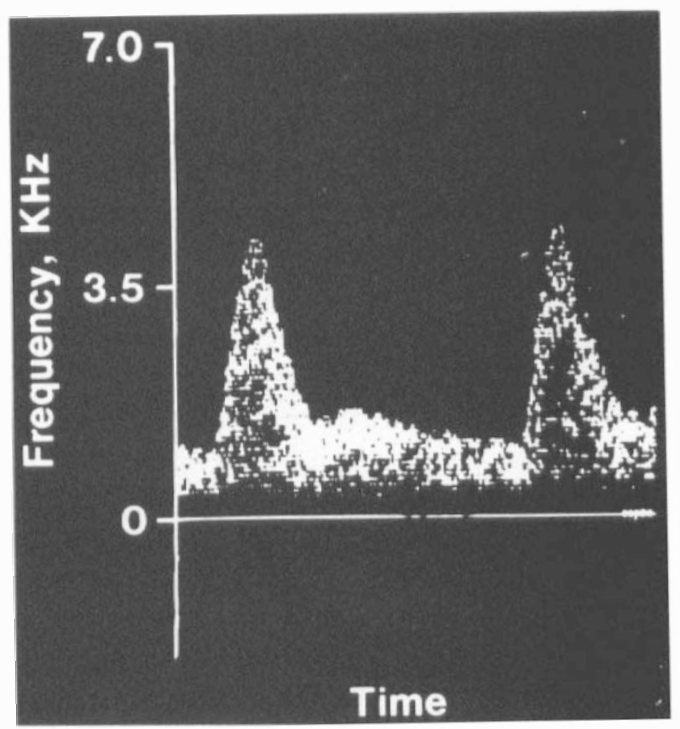




\section{Discussion}

The presence of autonomic dysfunction in quadriplegia is well established. Anatomically it is known that descending pathways from the hypothalamus and other regions of the central nervous system synapse with preganglionic sympathetic efferents from $\mathrm{T}_{1}$ to $\mathrm{L}_{2}$. Therefore, in patients with spinal cord transection above this level there is dissociation of the brain from the sympathetic nervous system. Biochemically plasma noradrenaline levels are reduced in quadriplegics at rest whether of recent or more chronic injury (Mathias et al., $1975 ;$ 1979). This loss of supra-spinal inhibition explains episodes of autonomic dysreflexia which occur in response to cutaneous and visceral stimuli. These are accompanied by a rise in noradrenalin levels but not adrenaline or plasma renin activity, suggesting a so-called 'sympathetic storm' (Corbett et al., 1971; Frankel et al., 1979; Tsai et al., 1980).

Distal arteriovenous shunting has been demonstrated in diabetics, although its aetiology is unclear. Our results show significantly increased venous oxygen concentrations in the feet of quadriplegics when compared with controls, suggesting the presence of shunting. Any difference in environmental conditions could not explain such a marked difference $(8.28 \mathrm{kPa}$ vs $5.3 \mathrm{kPa}, \mathrm{p}<0.001)$. In addition, the forward flow pattern of the posterior tibial artery sonogram contrasts with the triphasic pattern of controls, under constant conditions. This confirms the presence of arteriovenous shunting in the quadriplegics and the triphasic pattern observed in the quadriplegics femoral arteries demonstrates this to be a distal phenomenon. Therefore, autonomic dysfunction is likely to be playing a major role in the development of shunting in the quadriplegic and this may also be the case in the diabetic.

Interestingly, although vein distension was not prominent in the quadriplegics as in diabetics (Ward et al., 1983), when supine, cannulation itself was much easier than in the controls.

It has also been suggested in diabetics that stiffened calcified vessels play a part in arteriovenous shunting (Edmonds, Roberts et al., 1982), as measured by an increased PWV and EM. However, in the quadriplegics the EM was in fact reduced, with normal ankle pressure indices suggesting, if anything, more distensible arteries without occlusive vascular disease.

Despite this, a forward flow pattern occurred and it may be that this abnormality, as in the diabetic, has some part to play in the development of foot and leg ulceration.

\section{References}

Boulton AJM, Scarpello JHB, Ward JD 1982 Venous oxygenation in the diabetic neuropathic foot: evidence of arteriovenous shunting? Diabetologia 22:6-8.

Corbett JL, Frankel HL, Harris PJ 1971 Cardiovascular reflex responses to cutaneous and visceral stimuli in spinal man. Journal of Physiology 215:395-409.

EDMONDS ME, MORRISON N, LAws JW, et al. 1982 Medial arterial calcification and diabetic neuropathy. British Medical Journal 284:928-930.

EDMonds ME, Roberts VC, Watkins PJ 1982 Blood flow in the diabetic neuropathic foot. Diabetologia 22:9-15.

Frankel HL, Mathias CJ 1979 Cardiovascular aspects of autonomic dysreflexia since Guttmann and Whitteridge 1947. Paraplegia 17:46-51. 
GosLING RG 1976 Extraction of physiological information from spectrum analysed Dopplershifted continuous wave ultrasound signals obtained non-invasively from the arterial system. In: I.E.E. Medical Electronics Monograph 1976: 18-22, p. 73. Eds. Hill DW, Watson BW. Peter Peregrinus Ltd.

Mathias CJ, Christensen NJ, Corbett JL, et al. 1975 Plasma catecholamines, plasma renin activity and plasma aldosterone in tetraplegic man, horizontal and tilted. Clinical Science Molecular Medicine 49:291-299.

Mathias CJ, Christensen NJ, Frankel HL, et al. 1979 Cardiovascular control in recently injured tetraplegics in spinal shock. Quarterly Journal of Medicine. New Series XLVIII 190:273-287.

SCARPEllo JHB, Martin TRP, WARD JD 1978 Blood flow velocity studies in diabetic subjects with neuropathic ulcers. Clinical Science 55:3P.

SMALlwood RH, Brown BH, Rodgers AW 1977 A real time frequency analyser for ultrasound signals. Journal of Medical Engineering and Technology I:221-222.

Tsai SH, SHIH CJ, SHYY TT, et al. 1980 Recovery of vasomotor response in human spinal cord transection. Journal of Neurosurgery 52:800-811.

WARD JD 1982 The diabetic leg. Diabetologia 22:141-147.

WARD JD, BARNES CG, Fisher DJ, et al. 1971 Improvements in nerve conduction following treatment in newly diagnosed diabetics. Lancet 1:428-431.

WARD JD, Boulton AJM, Sims JM, et al. 1983 Venous distension in the diabetic neuropathic foot. (A physical sign of arteriovenous shunting). Journal of the Royal Society of Medicine 76:1011-1014.

YAO YST, HOBBS JT, IRVINE WT 1969 Ankle systolic pressure measurements in arterial disease affecting the lower extremities. British Journal of Surgery 56:676-679. 